\title{
Current Trends in Health Insurance Systems: OECD Countries vs. Japan
}

\author{
Toshiyuki SASAKI, ${ }^{1}$ Masahiro IZAWA, ${ }^{1}$ and Yoshikazu OKADA ${ }^{1}$ \\ ${ }^{1}$ Department of Neurosurgery, Tokyo Women's Medical University, Tokyo
}

\begin{abstract}
Over the past few decades, the longest extension in life expectancy in the world has been observed in Japan. However, the sophistication of medical care and the expansion of the aging society, leads to continuous increase in health-care costs. Medical expenses as a part of gross domestic product (GDP) in Japan are exceeding the current Organization for Economic Co-operation and Development (OECD) average, challenging the universally, equally provided low cost health care existing in the past. A universal health insurance system is becoming a common system currently in developed countries, currently a similar system is being introduced in the United States. Medical care in Japan is under a social insurance system, but the injection of public funds for medical costs becomes very expensive for the Japanese society. In spite of some urgently decided measures to cover the high cost of advanced medical treatment, declining birthrate and aging population and the tendency to reduce hospital and outpatients' visits numbers and shorten hospital stays, medical expenses of Japan continue to be increasing.
\end{abstract}

Key words: medical insurance, health-care system, universal health insurance, Organization for Economic Co-operation and Development countries

\section{Introduction}

For the last four decades, Japan has had the highest life expectancy at birth. The reduction of infant and maternal mortality, beginning in the 1950s, had strong effect on life expectancy. Recognizing this demographic effect, beginning in 1961, under the Japanese legislation a universal health insurance coverage was established. From the 1960s until now (after achievement of the universal coverage), reductions in mortality rates were noted for adults and elderly people, mainly with cerebrovascular and ischemic heart diseases as a result of easy access to health care by patients. This allowed widespread use of antihypertensive drugs, which contributed to reduction in stroke and cardiovascular mortality. ${ }^{1)}$ The universal health insurance coverage is a system in which everyone in a society can access the health-care services they need without incurring any financial hardships. ${ }^{2)}$ However, health expenditure as a share of the gross domestic product (GDP) is rapidly increasing in recent years (Fig. 1), and available data show that the improvement in healthy life expectancy decelerated since 1990s. ${ }^{3)}$ The object of

Received October 31, 2014; Accepted December 4, 2014 this article is to analyze the differences among the health-care systems of the first section of Organization for Economic Co-operation and Development (OECD) countries and to investigate the current status of health and health insurance in Japan and the world from OECD Health Statistics 2013 in its second section.

I. Comparison of health insurance among the leading OECD countries

There are three major types of social healthcare systems: social insurance systems like Japan, France, and Germany, tax-based system like the United Kingdom and Sweden, and the United States-limited service to the elderly or disabled, called Medicare (Table 1). The universal health coverage has both advantages and disadvantages. The advantages in comparison with private insurance are that being based on solidarity, premiums are levied according to the ability to pay, and not on the risk of illness. ${ }^{4)}$ Comparing to a tax-based system, the advantage is that the benefit package is defined as an entitlement and is financed by contributions that are earmarked for health care. ${ }^{5)}$ Although individuals pay for their prescription medications, public health care is generally free 


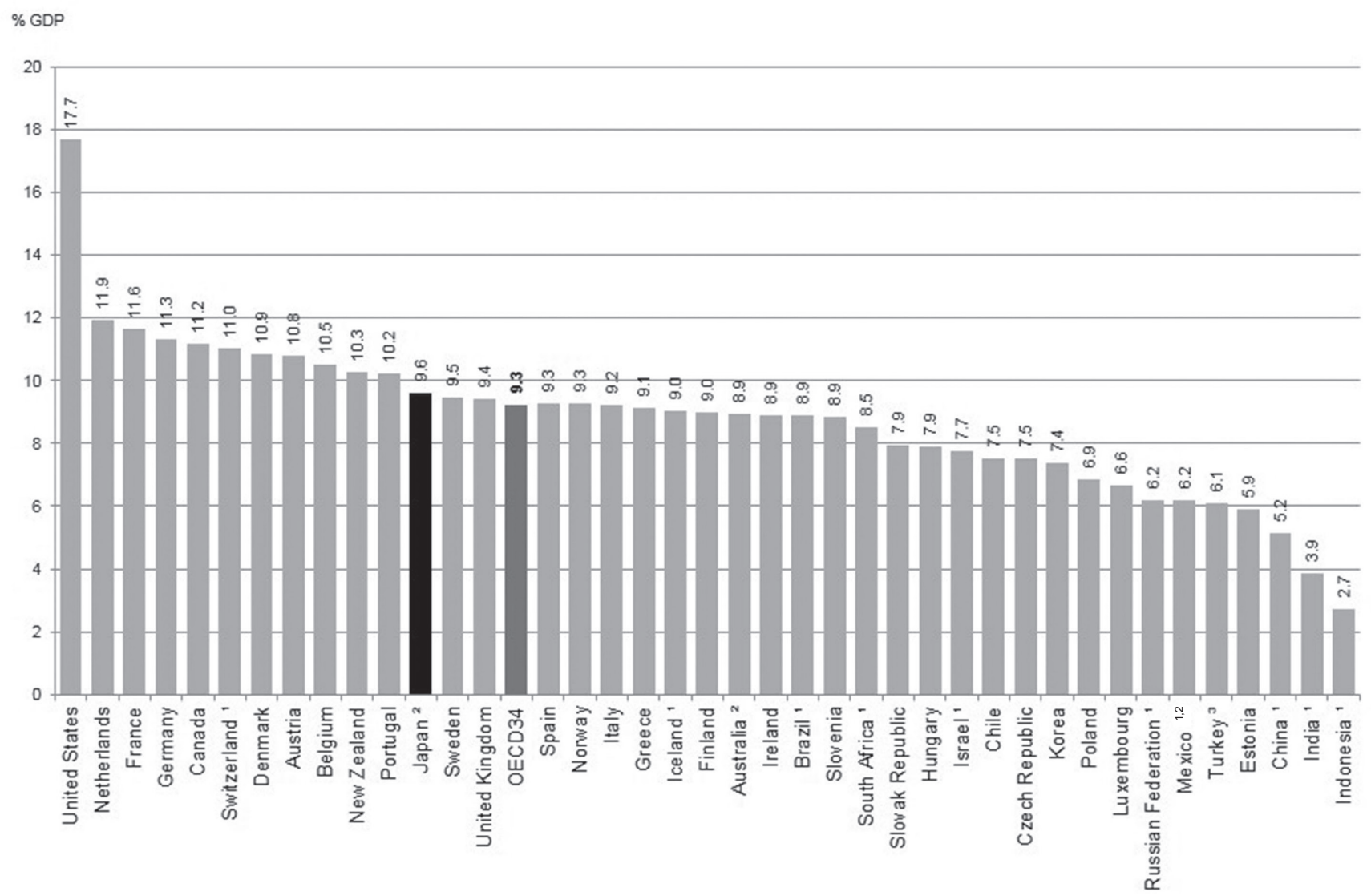

Fig. 1 Health expenditure as a share of gross domestic product in 2011 or nearest year. Graph showing Japanese health expenditure over the average of OECD countries. (1) Total expenditure only, (2) Data refers to 2010, and (3) Data refers to 2008. Source: OECD Health Statistics 2013. OECD: Organization for Economic Co-operation and Development.

of charge in the United Kingdom. However, in Sweden, Germany, and France, individuals must make certain contributions toward both medical examinations and prescription medications. Furthermore, relevant laws and regulations in Germany and France provide for chronic illnesses, and the individual contributions towards expensive or prolonged treatments in these countries are considerably lower compared to Japan's expensive health-care system. In this first section, we present some essential characteristics of the health-care system in each major OECD country.

Japan: A public, social insurance system, which provides universal health insurance coverage since 1961. Relatively early in the world, especially with an income per capita approximately half of that in the United Kingdom, ${ }^{6)}$ all Japanese citizens are provided with care and treatment at any time and at the place of their choice, regardless of the type of facility: public or private, level of care and as inor outpatients. The fundamental idea of this system is free access to high-quality health care. In Japan, health insurance is institutionalized in two major systems: the National Health Insurance, which generally covers self-employed people, students, farmers, and others, and Employees' Health Insurance, which covers salaried workers and their dependants and is categorized into six types: Seamen's insurance, government-managed insurance, union-managed insurance, mutual aid association for government employees, local government employees, and private school staff insurance. Additionally in 1973, a major revision of coverage in all plans took place, taking out co-payments once the monthly amount exceeded approximately 700 US dollars.

Currently the payment is $30 \%$ across the board for everybody, except for people aged 70 years and over with income below those of average workers, who pay $20 \%$ and children younger than 6 years, who pay $20 \%{ }^{6)}$

Japan's cost containment can primarily be attributed to its payment system: supply-side cost control is provided by the nationally uniform fee schedule for reimbursement, which is revised at both global and item-by-item level. ${ }^{7,8}$ The fee schedule controls the money flowing from all insurance plans to almost all 


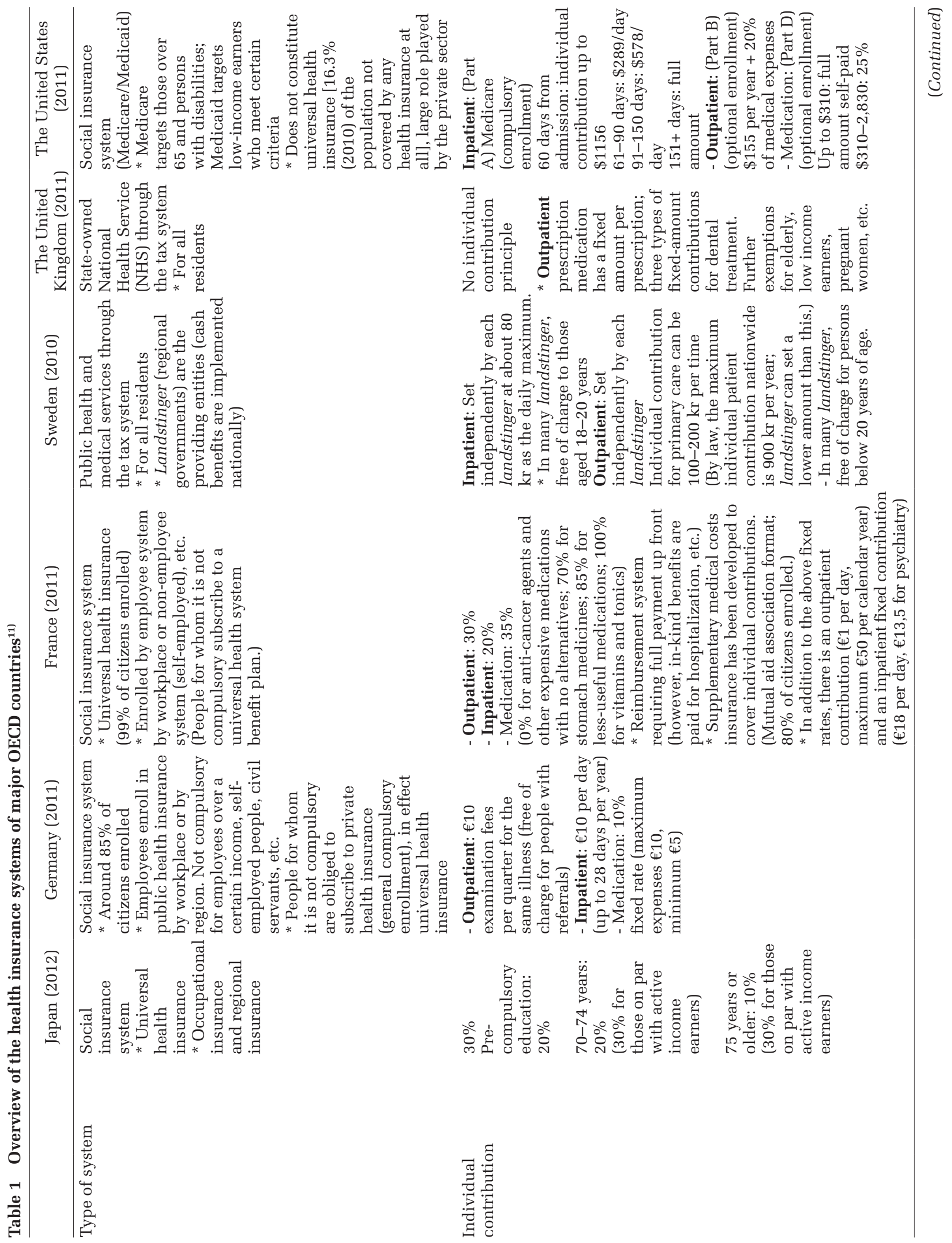

Neurol Med Chir (Tokyo) 55, April, 2015 


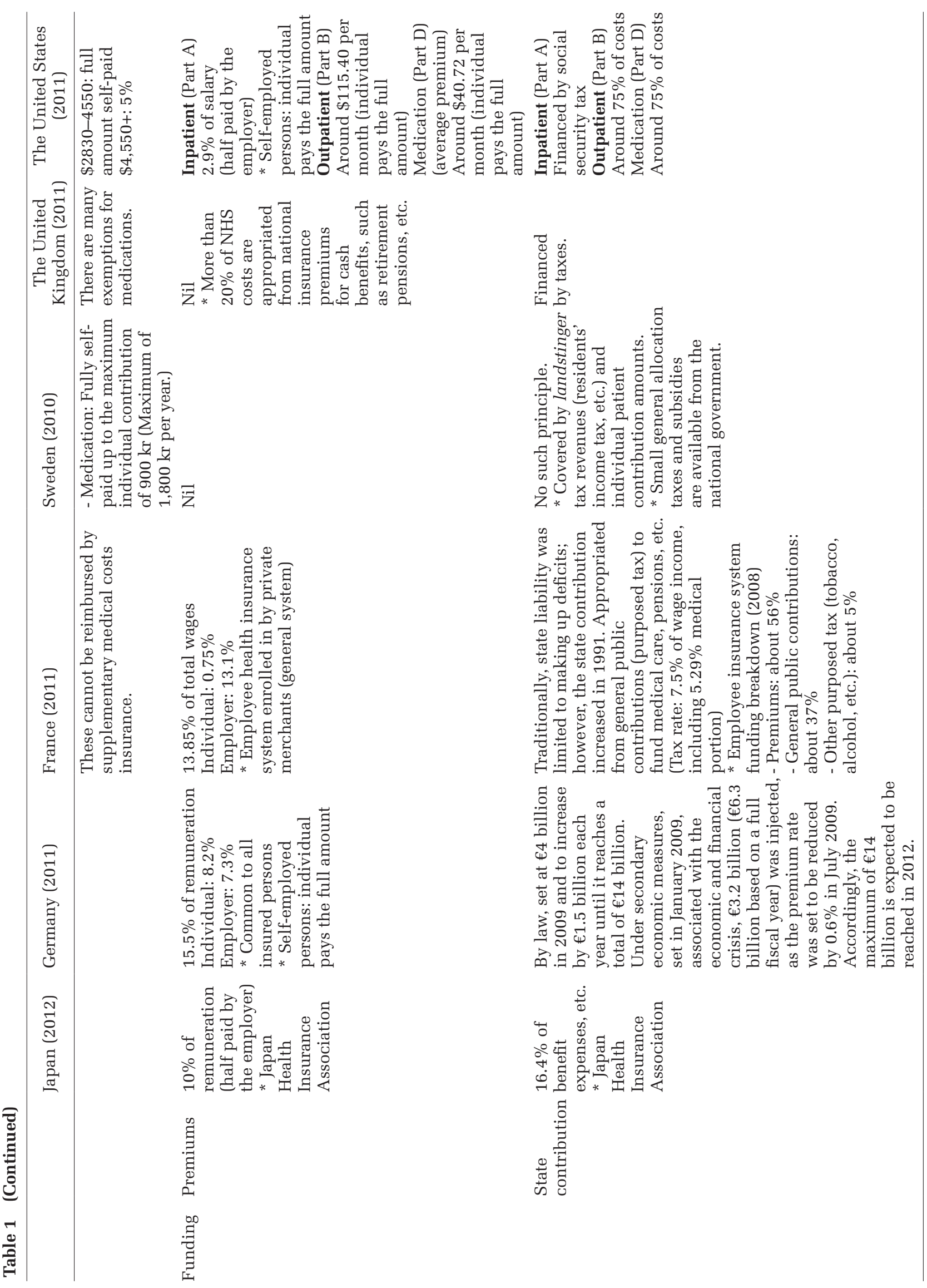


providers. Thus, although Japan has multiple payers (about 3,500 insurers), it has only one payment system that is applied across the board. This structure improves equity, since the benefit package is essentially the same for all social health insurance plans, and increases efficiency, since administrative costs are reduced. This also means that a revision of payment can be easy when the Cabinet decides on a global revision rate of all services and drug prices, based on the prime minister's evaluation of the nation's political and economic situation. During this process, the Ministry of Finance demands a rate decrease, the provider groups lobby for a rate increase, and the Ministry of Health, Labor, and Welfare plays a key part by providing technical expertise, especially regarding surgical fees of cardiovascular and neurological surgery. This revision is made every 2 years. ${ }^{7)}$ The price of drugs, devices, and services are revised on an item-by-item basis so that their net effect becomes equal to the global rate. The intended effect of making each revision depends on the volume of claims, which is estimated from the national claims data survey. These item-by-item decisions are offcially made by the Central Social Insurance Medical Council. The Japanese claim review process of the health insurance system has been reported in detail by Ito. ${ }^{9)}$ The providers send a claim to the insurers and get a reimbursement from the insurer. Recently, claim review process in the health insurance in Japan changed to online application. The peer-review board members check items of more than 20,000 items, set for each disease entity and the validity of the treatment is determined. The rejection of payment totals only $0.5 \%$ after the introduction of payment in combination of fee-for-service and a per-diem inclusive rate, as set by the Diagnosis Procedure Combination (DPC).

Germany: The German health-care system is a benefit-in-kind system provided through social insurance. Individual contributions constitute €10 per quarter for an outpatient visit, with a maximum of 28 visits per year. Individuals pay $10 \%$ of the cost of prescription medications, but they are free of charge for persons up to 18 years of age. Overall, the maximum annual amount of medical expense borne by the patient is $2 \%$ of the family annual income. This is limited to $1 \%$ for the disabled and patients with severe chronic illnesses. Pregnancyand childbirth-related costs are publicly funded with no individual contributions.

France: Medical services in France are provided through a workplace social security developed from a mutual aid system. The system functions through a compensation payment method, in which patients pay the full amount for outpatient examinations and prescription medication; then they receive a reimbursement from the medical insurer, while inpatient services are paid by insurer as benefits in kind. Since individual outpatient contributions are relatively high and only $60-70 \%$ of the payments are reimbursed, $80 \%$ of the citizens are enrolled in a supplementary medical costs insurance system to cover their individual out-of-pocket medical spending. Besides these fixed-amount patient contributions, outpatients also make contributions ( $€ 1$ per day, maximum of €50 per calendar year) and inpatient contributions (€18 per day).

Sweden: The Swedish health-care system operates as a public service funded by the landsting (county council) responsible for each county, through taxes, with set individual contributions. Individual outpatient contributions vary between landstings from 100 to 200 Swedish Kronas (kr) per examination, with a limit of $900 \mathrm{kr}$ per year for expensive medical treatments. The central government decides on matters relating to individual contributions and expensive medical treatments for inpatients.

The United Kingdom: The British health-care system is based on the National Health Service (NHS) and covers all residents. Although inpatient care and outpatient examinations are free of charge under the NHS, persons aged between 16 years and 60 years pay a certain fixed amount toward prescription medication.

The United States: The public health insurance systems are Medicare, which covers the elderly and the disabled, and Medicaid, which offers public assistance to low-income earners. Health insurance for the working population is primarily provided through private medical insurance. In the United States, $36 \%$ of the medical expenses are paid by private medical insurers, $19 \%$ by Medicare, $17 \%$ by Medicaid, and $16 \%$ by individual patients. ${ }^{10)}$ As medical expenses are high because health-care providers are private, the majority of insured obtain their policies on the private market in the United States. However, the number of those who do not have medical insurance through their workplace has been high particularly among the low-income earners, because premiums are paid in full by the insured. In that way the number of uninsured reached close to 50 million-one in sixth of the population). Therefore by subsidizing low-income earners, the Patient Protection and Affordable Care Act ("Obama-care") requiring enrollment in medical insurance for the public, has been promoted from 2014. By this reform, the government expects to increase to more than $90 \%$ the insurance rate in the United States. 


\section{Status of Japan among OECD countries: from OECD health statistics}

Access to health care: The OECD health care 2009 report mentioned the existence of four barriers to access health care. Such potential barriers include: (1) financial barriers (not being able to afford the costs of care), (2) geographic barriers (not having enough health-care providers in a particular geographic area or inconvenient very long travelling distance to providers), including racial, (3) cultural and information barriers (including language problems), and (4) barriers in terms of timely access (excessive waiting time to see providers). ${ }^{11)}$ Japan has none of these four barriers, so patients can access health care easier compared with other OECD countries.

Medical insurance coverage: Recently, most of the OECD countries have achieved universal or nearly universal health coverage for a core set of services, which usually include consultations with doctors and specialists, examinations, and surgical procedures. The percentage of population coverage reaches $100 \%$ for 22 of 31 OECD countries (Fig. 2). The percentages of public coverage for the core set of services are different, so in some countries, primary private health coverage is necessary. The percentages of private health insurance of total health expenditure are $35.1 \%$ in United States, $12.7 \%$ in France, $12.6 \%$ in Germany, $3.3 \%$ in United Kingdom, and only $0.3 \%$ in Japan. ${ }^{12)}$ Average length of stay in hospitals: The average length of stay in hospitals is a good indicator of medical efficiency because shorter stays tend to be more service intensive and more costly. The average stay in OECD countries was about 8 days, and here Japan differs with the longest, more than double of the average hospital stay of OECD countries (Table 2 ). In the recent years, hospital stay in Japan is getting shorter, promoted by the Ministry of Health, Labor, and Welfare.

Consultations with doctors: In many European countries, patients are required or given incentives to consult a general practitioner (GP) for any new condition and only then be referred to a specialist if necessary. However, Japan has no established GP system and in reality patients approach any specialist directly. This is considered an advantage of the Japanese free access policy, but that correlates with the highest number of specialist consultations in the OECD countries. The average number of specialist consultations per person in OECD countries was between 6 and 7 per person per year, but in Japan, this number was above 13 (Table 2). This becomes a disadvantage of the free access policy, as a direct result of everyone's access to any specialist in Japan, Japanese social aging and result of fee-for-service system of reimbursement.
- Total public coverage $\quad \square$ Primary private health coverage

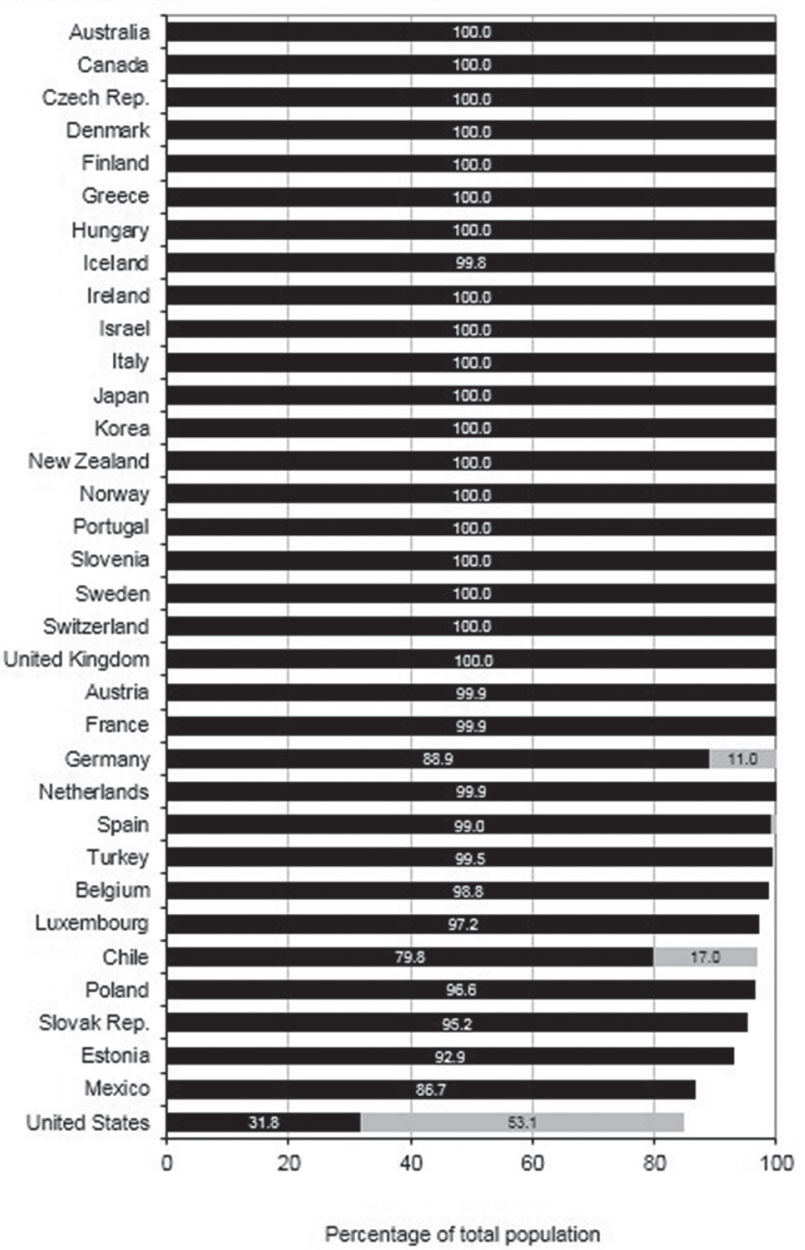

Fig. 2 Health insurance coverage for a core set of services. In 22 of the OECD countries health insurance coverage reached $100 \%$ in 2011. Source: OECD Health Statistics 2013. OECD: Organization for Economic Co-operation and Development.

Out-of-pocket medical expenditure: The measurement of out-of-pocket medical spending should be considered as a share of total household consumption. In the average of 34 OECD countries it was $2.9 \%$ and for Japan it was $2.2 \%$ (Table 2). The percentage was relatively low in the OECD countries and similar to Germany and France. ${ }^{13)}$ Moreover, the share of out-of-pocket as a share of total health expenditure is less than $15 \%$, which means in Japan burden on patients is not so high. Self-reported health and disability at age 65: In 12 of the 34 OECD countries, more than half of the population aged 65 years and over rate their health as "good." New Zealand, Canada, and the United States have the highest percentage of older people assessing their health to be good, and that is above $70 \%$. However, in Japan, less than $20 \%$ 
Table 2 Health-care use, expenditure, and resources in Japan compared with major OECD countries

\begin{tabular}{|c|c|c|c|c|c|c|c|}
\hline & Japan & Germany & France & Sweden & $\begin{array}{l}\text { The United } \\
\text { Kingdom }\end{array}$ & $\begin{array}{l}\text { The United } \\
\text { States }\end{array}$ & $\begin{array}{c}\text { OECD } \\
\text { average }\end{array}$ \\
\hline $\begin{array}{l}\text { Medical insurance } \\
\text { coverage }\end{array}$ & Public 100\% & $\begin{array}{l}\text { Public } 88.9 \% \\
\text { Private } 11.0 \%\end{array}$ & Public 99.9\% & Public 100\% & Public 100\% & $\begin{array}{l}\text { Public } 31.8 \% \\
\text { Private } 53.1 \%\end{array}$ & NA \\
\hline $\begin{array}{l}\text { Average length of } \\
\text { stay in hospital }\end{array}$ & 17.9 & 9.3 & 9.2 & 5.5 & 7.3 & 6.1 & 6.0 \\
\hline $\begin{array}{l}\text { Consultation with } \\
\text { doctors/year }\end{array}$ & 13.1 & 9.7 & 6.8 & 3.0 & 5.0 & 4.1 & 6.7 \\
\hline $\begin{array}{l}\text { Out-of-pocket } \\
\text { medical } \\
\text { expenditure/ } \\
\text { household } \\
\text { consumption }\end{array}$ & $2.2 \%$ & $1.8 \%$ & $1.5 \%$ & $3.3 \%$ & $1.5 \%$ & $2.9 \%$ & $2.9 \%$ \\
\hline $\begin{array}{l}\text { Self-reported health } \\
\text { and disability at } \\
\text { age } 65\end{array}$ & $18.4 \%$ & $38.7 \%$ & $37.3 \%$ & $63.2 \%$ & $59.5 \%$ & $75.2 \%$ & $42.2 \%$ \\
\hline $\begin{array}{l}\text { Generic market } \\
\text { share }\end{array}$ & $9 \%$ & $35 \%$ & $12 \%$ & NA & $28 \%$ & NA & $19 \%$ \\
\hline
\end{tabular}

Source: OECD Health Statistics 2013. GDP: gross domestic product, OECD: Organization for Economic Co-operation and Development, NA: not applicable.

of the population aged 65 and over report being in good health (Table 2).

Medical technologies: With the development of new medical technologies, the cost of the optimal disease management increases and that becomes one of the reasons of increasing health spending. In the last two or three decades, most OECD countries rapidly developed the availability of computed tomography (CT) scanners and magnetic resonance imaging (MRI) units. Japan has the highest number of MRI (46.9 units per million population) and CT scanners (101.3 units per million population) followed by the United States for MRI units and Australia for CT scanners. The average of MRI units in OECD countries was 13.3 units and that of CT scanners was 23.6 units. These data give us one of the reasons of high quality health care in Japan (Table 3).

\section{Discussion}

In the 1970s and 1980s, after the inception of universal coverage, the expansion of the Japanese economy was able to keep pace with the increasing financial burden. In 2000, World Health Organization (WHO) made a world health report 2000-health systems: improving performance (WHO Health Report 2000). In this report, WHO confidently concluded that in terms of quality care, Japan is the world leader and ranked number one among the 191 countries with respect to Overall Health
Table 3 Medical technologies about MRI units and CT scanners in 2011

\begin{tabular}{lcc}
\hline Country & $\begin{array}{c}\text { MRI units } \\
\text { number }\end{array}$ & $\begin{array}{c}\text { CT scanners } \\
\text { number }\end{array}$ \\
\hline Japan & 46.9 & 101.3 \\
The United States & 31.5 & 40.9 \\
Korea & 21.3 & 35.9 \\
OECD average & 13.3 & 23.6 \\
Germany & 10.8 & 18.3 \\
France & 7.5 & 12.5 \\
The United Kingdom & 5.9 & 7.3 \\
\hline
\end{tabular}

Per million population

Source: OECD Health Statistics 2013. CT: computed tomography, MRI: magnetic resonance imaging, OECD: Organization for Economic Co-operation and Development.

System Attainment. Furthermore, Japan also ranked ninth among the 191 countries according to Health System Performance. ${ }^{14)}$

According to the OECD Health Statistics 2013, Japanese health expenditure as a share of GDP in 2010 is $9.6 \%$. This is the first year for Japan to exceed the OECD average as a share of GDP (9.3\%) spent on health and that was a warning sign (Fig. 1). Meanwhile was believed that health expenditure was lower than other OECD countries. Unfortunately, total health spending in Japan has increased rapidly by approximately $5 \%$ per year in recent years. Main 
reason is the rapid aging of the population combined with the diminishing number of income-generating population. On average across OECD countries, the share of the population aged over 65 years has increased from less than $9 \%$ in 1960 to $15 \%$ in 2010 and is expected to nearly double in the next four decades to reach $27 \%$ in 2050 . In about two-thirds of the OECD countries, at least one-quarter of the population will be over 65 years of age by 2050 . This proportion is expected to be especially large in Japan, Korea, and Spain where nearly $40 \%$ of the population will be aged over 65 years by 2050 . Furthermore in Japan, the proportion of people aged 65 years and over in the population will increase from $22 \%$ in 2008 to $30 \%$ in 2020 , therefore, their share of health expenditure is projected to increase from $52 \%$ to $66 \% .{ }^{15)}$ The population aged over 80 years presage for Japan will be over 15\% in 2050 . This data indicate an accelerating pace of Japanese health expenditure increase in near future.

Japan should implement some countermeasures to these tendencies urgently. The most serious factor that should be tackled is low total fertility rate. Because of the trend toward delaying marriage, the rate decreased to 1.26 in 2005 and recovered to 1.43 in 2013. However this rate is still lower than France, United Kingdom, Switzerland, and the United States of America. These countries are able to keep the rate around 2.0. Japanese government and Ministry of Health, Labor, and Welfare should implement appropriate measures to improve this factor.

In Japan, the number of doctor consultations has the highest incidence in the OECD countries and is about the double of the average rate across the board for advanced hospital treatment, for example University hospitals. Most of the acute care in hospitals is now paid for by a combination of fee-for-service and a per-diem inclusive rate set by the DPC, which was introduced in 2003. ${ }^{16)}$ The main reason is that Japan has only fee-for-service system of reimbursement for outpatients on the background of not having GP system. For patients under acute care, mortality ratios were significantly lower in hospitals with a high number of full-time-equivalent physicians and pharmacists, particularly if they had a greater number of subspecialty departments, intensive care beds, general anesthesia procedures, and a greater ratio of inpatient to outpatient service volume. ${ }^{17}$ ) This is the reason why the Japanese population tends to visit large hospitals. However advanced treatment hospitals have to decrease their outpatient numbers to concentrate on the implementation of highly-advanced medical technologies.

The share of out-of-pocket to total health expenditure is less than $15 \%$ in Japan and its share of total household consumption is $2.2 \%$, which is lower than the average for the 34 OECD countries. If the out-of-pocket payment is very low, the number of medical doctor consultations excessively increases and conversely, if this payment is too high, patients in need refrain from hospital visits and disease progression may impact health status of population and increase expenses. Here establishing the proper balance is the most important.

The aging of the population has indicated large increase in health-care costs in recent years. On the other hand, the sophistication of medical care also has significant impact on the increase of health-care costs. Recently in order to suppress the medical expenses, as a part of the Choosing Wisely initiative, the American Association of Neurological Surgeons (AANS) and Congress of Neurological Surgeons (CNS) have released a list of five things physicians and patients should question for procedures in neurosurgery that are commonly ordered, but not always necessary, as below: ${ }^{18)}$

1. Don't administer steroids after severe traumatic brain injury.

2. Don't perform imaging (plain radiography, MRI, CT, or other advanced imaging) of the spine in patients with nonspecific acute low back pain and without red flags.

3. Don't routinely obtain CT scans of children with mild head injuries.

4. Don't routinely screen for brain aneurysms in asymptomatic patients without a family or personal history of brain aneurysms, subarachnoid hemorrhage (SAH), or genetic disorders that may predispose to aneurysm formation.

5. Don't routinely use seizure prophylaxis in patients following ischemic stroke.

Japanese neurosurgeons should keep in mind these five recommendations from AANS and CNS to reduce unnecessary testing and maintain the Universal Health Coverage System. However, Japanese patients who suffered from headache or mild head injury expect CT scanner or MRI when they visit a clinic, and as Japan has the highest number of CT scanners and MRIs in the world, these examinations can be performed the same day. Considering Choosing Wisely, in Japan awareness of both doctor and patient is necessary.

Pharmaceutical expenditure in Japan is also higher than that in Germany, Sweden, and France. That means generic drug market share is smaller than in other countries (only 9\% in Japan for 2011). It is certainly necessary to promote the use of generic drugs in Japan.

The Japanese government is trying the remodeling of social security and taxation. From April 2014, 
government raised the value added tax from $5 \%$ to $8 \%$, and will attempt to raise it to $10 \%$ from October 2015. That will help to improve the public expenditure from general tax revenues (around 40\% of National Health Insurance expenditure) of the Japanese health-care system and will enhance social security, contributing to improve the existing low rate of self-reported in good health.

\section{Conclusion}

Japan for the first time in the world introduced a national health insurance that provided equal medical care with appropriate standards. However, the increase in health-care costs due to aging is one of the most important changes for society in Japan. Medical care in Japan is a social insurance system, but the injection of public funds to the medical costs is very expensive already and will be more in the future, exerting big pressure on the finances of the country. The familiar with the system medical institutions should understand the role of medical fees and correctly balance between the National Health Insurance Federation and Social Insurance Medical Fee Payment Fund and patients. Neurosurgery as one of the most technologically advanced specialties shall find a proper solution for providing adequate patient care in this environment of restrictions.

\section{Acknowledgment}

The authors would like to thank Osami Kubo, MD, Former Professor of Neurosurgery, Tokyo Woman's Medical University School of Medicine, Tokyo, for his invaluable advice.

\section{Conflicts of Interest Disclosure}

The authors declare that they have no conflicts of interest.

\section{References}

1) Ikeda N, Saito E, Kondo N, Inoue M, Ikeda S, Satoh T, Wada K, Stickley A, Katanoda K, Mizoue T, Noda M, Iso H, Fujino Y, Sobue T, Tsugane S, Naghavi M, Ezzati M, Shibuya K: What has made the population of Japan healthy? Lancet 378: 1094-1105, 2011

2) WHO: Sustainable health financing, universal coverage and social health insurance. World Health Assembly, Geneva 2005.

3) Hashimoto S, Kawado M, Seko R, Murakami Y, Hayashi M, Kato M, Noda T, Ojima T, Nagai M, Tsuji I: Trends in disability-free life expectancy in Japan, 1995-2004. J Epidemiol 20: 308-312, 2010
4) Saltman RB, Busse R, Figueras J (eds): Social health insurance systems in Western Europe. Maidenhead, Open University Press, 2004.

5) Hisao WC. Design and implementation of social health insurance, in Hisao WC, Shaw RP (eds): Social Health Insurance for Developing Nations. Washington, DC, World Bank, 2007, pp 21-41

6) Ikegami N, Yoo BK, Hashimoto H, Matsumoto M, Ogata H, Babazono A, Watanabe R, Shibuya K, Yang BM, Reich MR, Kobayashi Y: Japanese universal health coverage: evolution, achievements, and challenges. Lancet 378: 1106-1115, 2011

7) Ikegami N, Campbell JC: Japan's health care system: containing costs and attempting reform. Health Aff (Millwood) 23: 26-36, 2004

8) Wagstaff A: Health Systems in East Asia: What Can Developing Countries Learn from Japan and the Asian Tigers? Policy Research Working Paper 3790. Washington, DC, World Bank, 2005

9) Ito M: Health insurance systems in Japan: a neurosurgeon's view. Neurol Med Chir (Tokyo) 44: 617-628, 2004

10) Ministry of Health, Labor and Welfare. Tokyo: International Data of Medical Insurance (Japanese). <http://www.mhlw.go.jp/stf/seisakunitsuite/bunya/ kenkou_iryou/iryouhoken/iryouhoken11/index.html>

11) OECD Health at a Glance 2009: OECD Indicators, 2009. http://oecd-ilibrary.org/conten/book/health_ glance-2009-en

12) OECD Health Working Paper 2004. http://www. oecd.org/els/health-systems/33698043

13) OECD Health at a Glance 2013. http://www.oecdilibrary.org/social-issues-migration-health/health-ata-glance-2013_health_glance-2013-en

14) World Health Organization: WHO Health Report 2000-Health Systems: Improving Performance. http:// www.who.int/whr/2000/en/

15) Ministry of Health, Labor and Welfare: Data 3; projections for national medical expenditures. Tokyo, Ministry of Health, Labor and Welfare, 2005

16) Matsuda S, Ishikawa K, Kuwabara K, Fujimori K, Fushimi K, Hashimoto H: Development and use of the Japanese case-mix system. Euro Health 14: 25-30, 2008

17) Hashimoto $H$, Ikegami $N$, Shibuya $K$, Izumida $N$, Noguchi H, Yasunaga H, Miyata H, Acuin JM, Reich MR: Cost containment and quality of care in Japan: is there a trade-off? Lancet 378: 1174-1182, 2011

18) An initiative of the ABMI foundation: Five things physicians and patients should question. Choosing Wisely, 2014. http://www.choosingwisely.org/

Address reprint requests to: Toshiyuki Sasaki, MD, PhD, Department of Neurosurgery, Tokyo Women's Medical University, 8-1 Kawada-cho, Shinjuku-ku, Tokyo 160-8666, Japan e-mail: tsasaki@nij.twmu.ac.jp 